\title{
Proton-coupled Reduction of the Catalytic [4Fe-4S] Cluster in [FeFe]-hydrogenases
}

\author{
Moritz Senger ${ }^{[a]}$, Konstantin Laun ${ }^{[a]}$, Florian Wittkamp ${ }^{[b]}$, Jifu Duan ${ }^{[c]}$, Thomas Happe ${ }^{[c]}$, Martin Winkler ${ }^{[c]}$, \\ Ulf-Peter Apfe[ ${ }^{[b] *}$, Sven T. Stripp ${ }^{[a] * *}$
}

\begin{abstract}
FeFe]-hydrogenases catalyze the uptake and release of molecular hydrogen $\left(\mathrm{H}_{2}\right)$ at a unique iron-sulfur cofactor. The absence of electrochemical overpotential in the $\mathrm{H}_{2}$ release reaction makes [FeFe]-hydrogenases a prime example of efficient biocatalysis. However, the molecular proceedings of hydrogen turnover are not understood yet. In this study, we characterize the initial one-electron reduction of [FeFe]-hydrogenases by infrared spectroelectrochemistry and present evidence for proton-coupled electron transport in the formation of the reduced state Hred'. Charge compensation stabilizes the excess electron at the [4Fe-4S] cluster and maintains a conservative configuration of the diiron site. The role of Hred' in hydrogen turnover and possible implications on the catalytic mechanism are discussed.
\end{abstract}

Hydrogenases are gas-processing metalloenzymes that exploit earth-abundant nickel and iron ions to catalyze the uptake and release of molecular hydrogen $\left(\mathrm{H}_{2}\right) .{ }^{[1]}$ The bioinorganic cofactors of hydrogenases represent natural blueprints for the design of catalysts with potential value in sustainable $\mathrm{H}_{2}$ production. ${ }^{[2-6]}$ For example, in [FeFe]-hydrogenases a [6Fe-6S] complex has been identified. ${ }^{77,8]}$ The "H-cluster" comprises a canonical, low-spin [4Fe-4S] cluster covalently linked to a unique diiron site (Fig. 1). Hydrogen turnover occurs at the iron ion located most distal to the [4Fe-4S] cluster $\left(\mathrm{Fe}_{\mathrm{d}}\right) .{ }^{[9-11]}$ Catalysis involves an aminodithiolate group (adt) that has been shown to serve as pendant base for heterolytic $\mathrm{H}_{2}$ oxidation at $\mathrm{Fe}_{\mathrm{d}}{ }^{[12,13]}$

Different redox states of the $\mathrm{H}$-cluster have been described (Tab. S1). This includes the active-ready, oxidized state Hox characterized by a mixed-valence diiron site and an oxidized [4Fe-4S] cluster. ${ }^{[14]}$ Hred and Hred' represent two distinct oneelectron reduced species. The former carries an extra electron at the diiron site while the latter shows a reduced [4Fe-4S] cluster. ${ }^{[15-18]}$ Redox species with two supplemental electrons are Hsred and Hhyd. The "super-reduced" state Hsred equals Hred with an additional electron at the [4Fe-4S] cluster. ${ }^{[19]}$ The hydride state Hhyd represent an $\mathrm{H}_{2}$-activated species that has been shown to comprise a reduced [4Fe-4S] cluster and terminal hydride at the oxidized diiron site. ${ }^{[9-11]}$ In contrast, Hred and Hsred were suggested to bind a bridging hydride..$^{[20,21]}$ Please find a discussion on nomenclature in Supporting Information.

$[a]^{\star *} \quad$ M. Senger, K., Laun, Dr. Sven T. Stripp

Department of Physics, Freie Universität Berlin

Arnimallee 14, 1495 Berlin (Germany)

E-mail:sven.stripp@fu-berlin.de

[b] $]^{\star} \quad$ F. Wittkamp, Dr. U.-A. Apfel

Faculty of Chemistry and Biochemistry, Ruhr-Universität Bochum

Universitätstrasse 150, 44801 Bochum, (Germany)

E-mail: ulf.apfel@rub.de

[c] J. Duan, Dr. M. Winkler, Prof. Dr. T. Happe

Faculty of Biology and Biotechnology, Ruhr-Universität Bochum Universitätsstrasse 150, 44801 Bochum (Germany)

Supporting information for this article is given via a link at the end of the document.

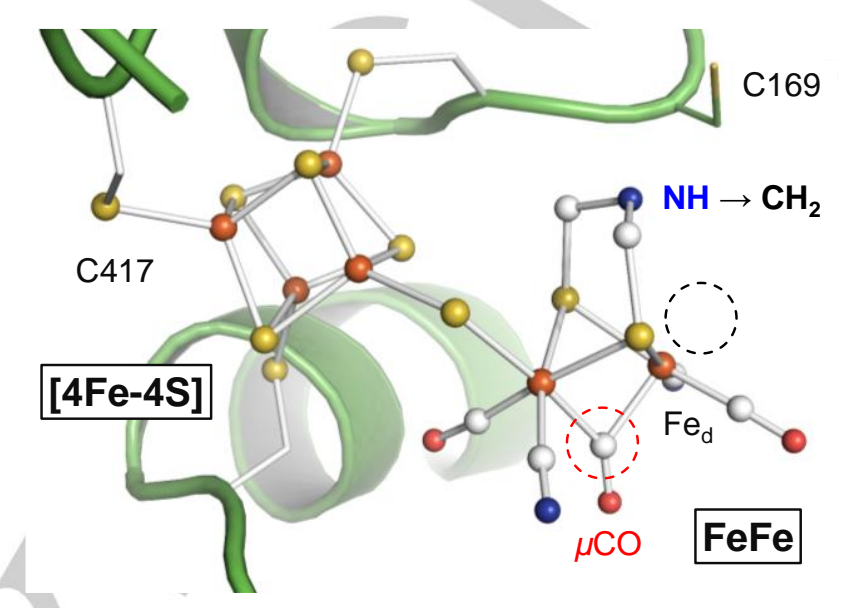

Figure 1. Active site of [FeFe]-hydrogenases. [4Fe-4S] cluster and diiron site form the $\mathrm{H}$-cluster (4XDC). Hydrogen catalysis requires an open coordination site (black circle) and the secondary amine $(\mathrm{NH})$ of the native dithiolate group, adt. The $\mathrm{NH}$ head is replaced by methylene $\left(\mathrm{CH}_{2}\right)$ in cofactor variant pdt. Oxidation of the diiron site stabilized a carbon monoxide ligand in $\mathrm{Fe}-\mathrm{Fe}$ bridging position (red circle, $\mu \mathrm{CO}$ ). In HYDA1, protonation of the [4Fe-4S] cluster involves $\mathrm{C} 417$. Cysteine 169 is the primary proton relay to the diron site.

Recent advancements in post-translational protein modification allow generating [FeFe]-hydrogenases with non-natural cofactors and addressing protonation/ reduction dynamics in otherwise native enzyme. ${ }^{[22-24]}$ For example, cofactor variant HYDA $1^{\text {pdt }}$ enhances the hydrophobicity of the dithiolate bridge by a methylene headgroup (Fig. 1) ${ }^{[22]}$ While spectro-electrochemistry demonstrated the presence of Hox and Hred' in HYDA $1^{\text {pdt }}$ neither Hred nor Hsred were observed. ${ }^{[15,23]}$ This supports the assumption that Hred formation is associated with a protonation event at the diiron site. ${ }^{[16]}$ Making use of $\mathrm{pH}$ - and redox titrations, we could demonstrate the existence of protonated species HoxH and Hred'H in HYDA $1^{\text {pdt }}$ and native hydrogenase. Density functional theory calculations (DFT) supported a protonation at the [4Fe-4S] cluster. ${ }^{[17]}$ While frequency correlation suggested a protonated [4Fe-4S] cluster for Hred' as well, experimental proof for this claim is missing. We herein follow up on this proposal and use a novel attenuated total reflection Fourier-transform infrared (ATR FTIR) spectro-electrochemistry set-up (Fig. S1) to probe the

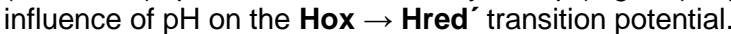

The stretching frequencies of the $\mathrm{CO} / \mathrm{CN}^{-}$ligands at the diiron site can be explored to analyze the electronic structure of the $\mathrm{H}$ cluster by IR spectroscopy. ${ }^{[25-28]}$ Figure 2 shows the vibrational profile of $\mathrm{H}$-cluster species populated in $\mathrm{HYDA} 1^{\text {pdt }}$ at different $\mathrm{pH}$ values and increasingly reducing cell potentials. At $-350 \mathrm{mV}$ vs SHE the enzyme mainly adopted the oxidized state Hox while Hred' was the dominating species at $-650 \mathrm{mV}(\mathrm{pH} 7.5)$. The protonated, oxidized state $\mathrm{HoxH}$ was enriched at $-150 \mathrm{mV}$ and Hred'H dominated at $-450 \mathrm{mV}(\mathrm{pH} 5.5)$. Reduced and oxidized species differ by a shift of up to $12 \mathrm{~cm}^{-1}$. The protonated species show a $4 \mathrm{~cm}^{-1}$ up-shift relative to Hox and Hred' (Tab. S2). 

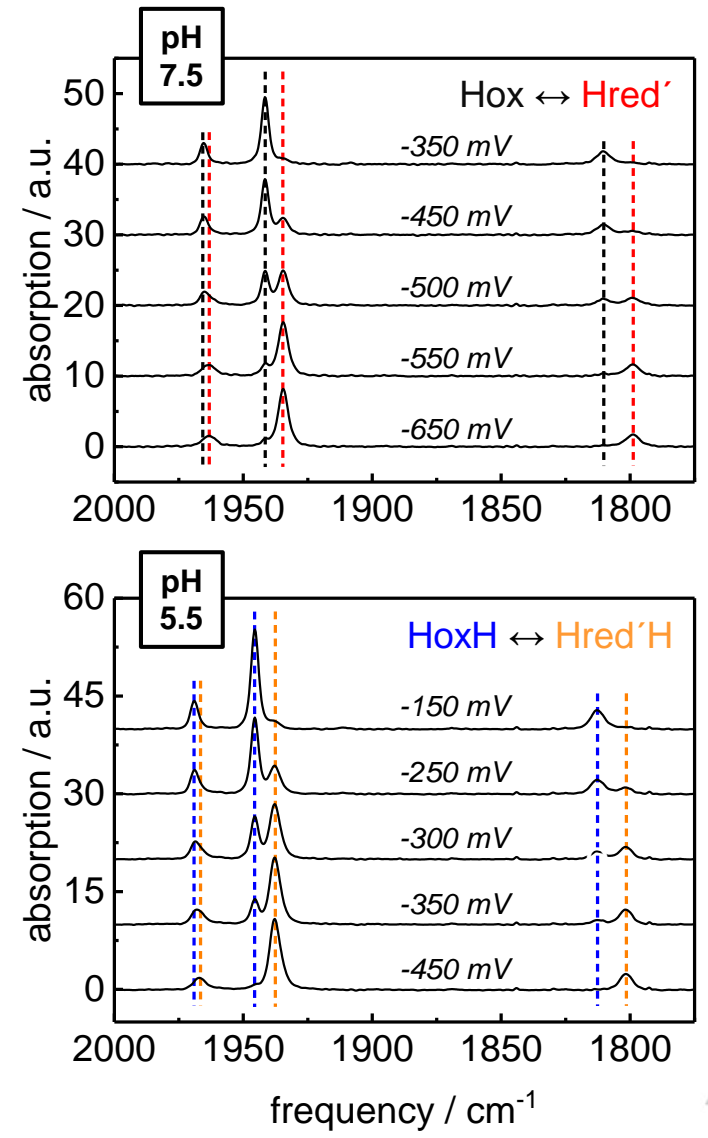

Figure 2. FTIR spectro-electrochemistry on cofactor variant HYDA1 ${ }^{\text {pdt }}$. The $\mathrm{CO}$ frequency regime is shown for cell potentials from -150 to $-650 \mathrm{mV}$ vs SHE (see Fig. S2 for $\mathrm{CN}^{-}$frequencies). The electrolyte buffer was enriched with 10 $\mathrm{mM}$ dithionite and set to either $\mathrm{pH} 7.5$ or $\mathrm{pH}$ 5.5. Oxidizing potentials facilitated the population of Hox and HoxH while at reducing potentials, Hred' and Hred'H dominated.

Sommer and co-workers were able to show that protonation of the diiron site is crucial for formation of Hred in native enzyme (the authors refer to this state as " $\mathrm{HredH}^{+}$", see Supporting Information). ${ }^{[16]}$ Similar PCET reactivity at the [4Fe-4S] cluster was implied by our DFT frequency calculations for Hred'. ${ }^{[17]}$ To experimentally verify the calculated spectra, we probed the Hox

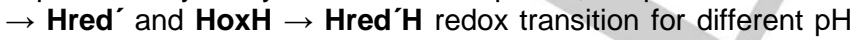
values. The absence of a pendant base in the dithiolate group of HydA $1^{\text {pdt }}$ prevents protonation of the diiron site and, thus, formation of Hred and Hsred. This allows addressing the redox chemistry of the [4Fe-4S] cluster directly. In Fig. 3, changes in relative population were plotted against cell potential to identify the transition potentials (see Fig. S2 for details). Traces were fitted according to Nernstian behavior for one electron. ${ }^{[15-17]}$ The population diagrams illustrate how this facilitated analyzing all transitions simultaneously. While the HoxH/ Hred'H redox couple clearly dominated at $\mathrm{pH} 5.5$, only a small percentage of protonated species was detected at $\mathrm{pH}$ 7.5. Oxidizing potentials facilitated a mix of $\mathbf{H o x}$ and $\mathbf{H o x H}$ at $\mathrm{pH} 6.5$.
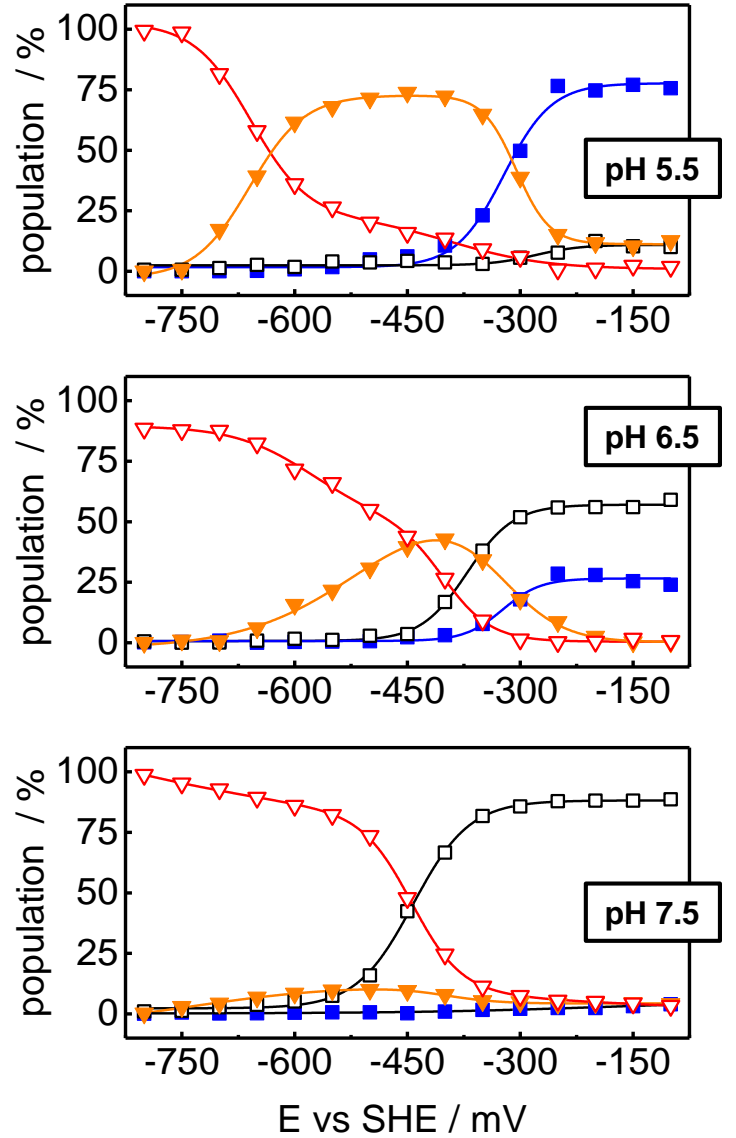

Figure 3. Population diagrams for chosen $\mathrm{pH}$ values. Changes in the relative population of species (\%) as a function of cell potential $(\mathrm{mV})$ and proton concentration. Observed redox species include Hox (black), HoxH (blue), Hred (red), and Hred'H (orange). See Fig. S3 for the full set of investigated pH valules.

The Pourbaix diagram in Fig. 4 shows the evaluation of transition potentials for Hox $\rightarrow$ Hred' and HoxH $\rightarrow$ Hred'H from $\mathrm{pH} 5.5$ to 7.5 and -300 to $-450 \mathrm{mV}$ (see Fig. S3 for the complete data set). In general, lower $\mathrm{pH}$ values propagated sample reduction at less negative potentials. Linear regression with $55 \pm 5 \mathrm{mV} / \mathrm{pH}(\mathrm{Hox} \rightarrow$ Hred' $^{\prime}$ ) and $50 \pm 3 \mathrm{mV} / \mathrm{pH}\left(\right.$ HoxH $\rightarrow$ Hred'H) was detected $\left(\mathrm{R}^{2}=\right.$ 0.96 and 0.98 , respectively). While both slopes were found to be significantly similar the off-set of about $50 \mathrm{mV}$ to less negative potentials for HoxH $\rightarrow$ Hred'H suggests that protonation of the [4Fe-4S] cluster directly affects the transition potential. In Fig. 4 the blue curve clearly lies above the $\mathrm{H}_{2} / \mathrm{H}$ reference potential (dashed line, red) which explains the spontaneous reduction of HYDA $1^{\text {pdt }}$ in presence of $\mathrm{H}_{2}$ as reported previously. ${ }^{[17]}$ The Hred' $\mathbf{H}$ $\rightarrow$ Hred' transition under strongly reducing conditions $\mathrm{E}<-600$ $\mathrm{mV}$ is independent of $\mathrm{pH}$ (Fig. S4). 


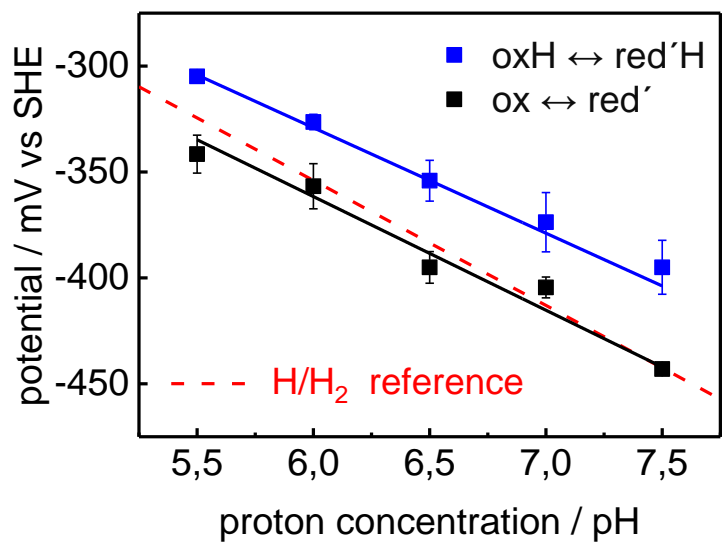

Figure 4. Pourbaix diagram. The transition potentials for Hox $\rightarrow$ Hred' (black) and $\mathrm{HoxH} \rightarrow$ Hred'H (blue) as a function of $\mathrm{pH}$ are shown. Slopes are $55 \pm 5$ $\mathrm{mV} / \mathrm{pH}$ (black) and $50 \pm 3 \mathrm{mV} / \mathrm{pH}$ (blue) with an approximate off-set of $\Delta 50 \mathrm{mV}$ that elevates the $\mathrm{HoxH} \rightarrow \mathrm{Hred}$ ' $\mathrm{H}$ potential above the $\mathrm{H} / \mathrm{H}_{2}$ reference (red traces, $59 \mathrm{mV} / \mathrm{pH}$ ). Error bars depict on the quality of the Nernstian fit.

\section{Conclusions}

In a $\mathrm{pH}$ titration on native HYDA1 we previously observed an accelerated enrichment of Hred' from $\mathrm{pH} 10-7$ however the preferential accumulation of Hred for $\mathrm{pH}<7$ restricted an unbiased analysis.[17] These trends suggested competitive protonation in the formation of Hred' and Hred. ${ }^{[15-17,19,20]}$ The slope of $55 \mathrm{mV} / \mathrm{pH}$ in Fig. 4 now clearly proves that formation of Hred' is coupled to a protonation event. While the Hox $\rightarrow$ Hred transition in native hydrogenase is associated with proton delivery to the diiron site ${ }^{[16]}$, formation of Hred' involves protonation of the [4Fe-4S] cluster. ${ }^{[17]}$ The latter is critically supported by our DFT calculations, the independence of Hred' from proton transfer via the adt group ${ }^{[15]}$, and the data presented herein. In both cases, PCET is the decisive feature whether excess charge is stabilized at the $[4 \mathrm{Fe}-4 \mathrm{~S}]$ cluster or at the diiron site.

The bridging $\mathrm{CO}$ ligand $(\mu \mathrm{CO})$ is replaced by $\mu \mathrm{H}$ in Hred and Hsred and occupies the $\mathrm{Fe}_{d}$ apical position (Fig. S5). ${ }^{[20]}$ This geometry was found to be incompatible with the rapid hydrogen turnover of [FeFe]-hydrogenases ${ }^{[29-34]}$, in particular due to the stability of bridging metal hydrides $(\mu \mathrm{H}) \cdot{ }^{[4]}$ We recently suggested HoxH/ Hred' as rate-limiting redox couple in the catalytic cycle. ${ }^{[17,35]}$ Both species share a $\mu \mathrm{CO}$ ligand and a protonated [4Fe-4S] cluster. In 2008, Singleton and co-workers pointed out the "formidable challenge (...) to maintain this rotated structure throughout the redox process". ${ }^{[36]}$ To promote efficient hydrogen turnover, protonation of the [4Fe-4S] cluster may be necessary to suppress premature reduction of the diiron site and preserve the "rotated" $\mu \mathrm{CO} \mathrm{H}$-cluster geometry.

A bridging carbonyl characterizes Hhyd as well. ${ }^{[9-11]}$ It is exciting to evaluate the IR signature of Hhyd by DFT calculations; here, significant oxidation of the diiron site is exclusively achieved when the terminal hydride is accompanied by a proton at the reduced [4Fe-4S] cluster. ${ }^{[35]}$ Protonation of the [4Fe-4S] cluster appears to be a prerequisite not only in the formation of Hred' but Hhyd, too.

We propose that Hred and Hsred constitute for less efficient hydrogen turnover, determined by the low probability of $\mu \mathrm{H}$ to rotate into a terminal position. ${ }^{[32-34]}$ In contrast, rapid hydrogen turnover likely includes Hred' and Hhyd (Fig. 5 and Fig. S5). ${ }^{[35]}$ Both these species stabilize an oxidized diiron site and "rotated" cofactor geometry by PCET to the [4Fe-4S] cluster. Based on our findings, we encourage the design of synthetic $\mathrm{H}$-cluster mimics that comprise redox-active ligands ${ }^{[37]}$, for example as recently demonstrated by Camara and Rauchfuss. ${ }^{[38]}$ Protonatable ligands may be exploited to control the localization of charges, stabilize a "rotated" cofactor geometry, and thus facilitate efficient hydrogen turnover.

Hox

HoxH

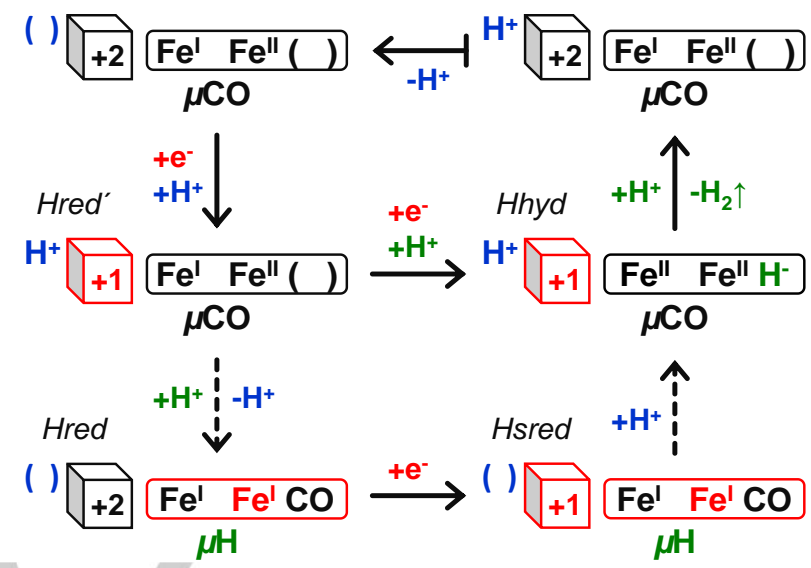

Figure 5. Catalytic cycle of hydrogen turnover $\left(\mathrm{H}_{2}\right.$ release). We assume no changes in the steady-state protonation of the dithiolate group (omitted for clarity). Upper left: Hox is converted into Hred' by PCET. The regulatory proton (blue) binds at a coordinating cysteine of the reduced [4Fe-4S] cluster (Fig. 1). Subsequent protonation and reduction of the diiron site results in the formation of Hhyd. The catalytic proton (green) occupies the apical position at the distal iron ion. Supply of the second catalytic proton and release of $\mathrm{H}_{2}$ recovers the oxidized resting state, here $\mathrm{HoxH}$ (upper right). This species is converted into $\mathrm{Hox}$ by release of the regulatory proton. We note that a direct reduction of $\mathrm{HoxH}$ into Hred' (ET) is conceivable but has not been observed experimentally; the involvement of $\mathrm{Hox}$ and/ or $\mathrm{HoxH}$ in the cycle remains to be evaluated. In the lower half, dashed arrows indicate transitions that involve structural rearrangements. The redox species Hred and Hsred are characterized by a reduced diiron site and bridging hydride $(\mu \mathrm{H})$.

\section{Acknowledgements}

MS and STS acknowledge funding by the IMPRS on Multiscale Biosystems and NanoScale. FW and UPA thank the Fonds der Chemischen Industrie (Liebig Grant), the DFG (AP242/2-1), and the Studienstiftung des deutschen Volkes for financial support. JD, $\mathrm{MW}$, and $\mathrm{TH}$ acknowledge funding by the Volkswagen Foundation (LigH2t), the DFG (EXC 1069), and the China Scholarship Council.

Keywords: Infrared Spectroscopy • Electrochemistry - Protoncoupled Electron Transfer $\bullet$ Hydrogen Turnover $\bullet$ Catalysis

\section{References}

[1] W. Lubitz, H. Ogata, O. Ru, E. Reijerse, Chem. Rev. 2014, 114, 4081-4148.

[2] G. J. Kubas, Chem. Rev. 2007, 107, 4152-205.

[3] C. Tard, C. J. Pickett, Chem. Rev. 2009, 109, 2245-2274.

[4] D. Schilter, J. M. Camara, M. T. Huynh, S. HammesSchiffer, T. B. Rauchfuss, Chem. Rev. 2016, 116, 86938749 . 
[5] B. Konkena, K. junge Puring, I. Sinev, S. Piontek, O. Khavryuchenko, J. P. Dürholt, R. Schmid, H. Tüysüz, M. Muhler, W. Schuhmann, et al., Nat. Commun. 2016, 7, 12269.

[6] F. Möller, S. Piontek, R. G. Miller, U.-P. Apfel, Chem. - A Eur. J. 2017, DOI 10.1002/chem.201703451.

[7] Y. Nicolet, C. Piras, P. Legrand, C. E. Hatchikian, J. C. Fontecilla-Camps, Structure 1999, 7, 13-23.

[8] J. W. Peters, W. N. Lanzilotta, B. J. Lemon, L. C. Seefeldt, Science 1998, 282, 1853-1858.

[9] D. W. Mulder, Y. Guo, M. W. Ratzloff, P. W. King, J. Am. Chem. Soc. 2016, 139, 83-86.

[10] E. J. Reijerse, C. C. Pham, V. Pelmenschikov, R. Gilbertwilson, A. Adamska-venkatesh, J. F. Siebel, L. B. Gee, Y. Yoda, K. Tamasaku, W. Lubitz, et al., J. Am. Chem. Soc. 2017, 139, 4306-4309.

[11] M. Winkler, M. Senger, J. Duan, J. Esselborn, F. Wittkamp, E. Hofmann, U.-P. Apfel, S. T. Stripp, T. Happe, Nat. commun. 2017, 8, 1-7.

[12] A. Silakov, B. Wenk, E. Reijerse, W. Lubitz, Phys. Chem. Chem. Phys. 2009, 11, 6553-4.

[13] G. Berggren, A. Adamska-Venkatesh, C. Lambertz, T. R. Simmons, J. Esselborn, M. Atta, S. Gambarelli, J.-M. Mouesca, E. J. Reijerse, W. Lubitz, et al., Nature 2013, 499, 66-9.

[14] A. Silakov, E. J. Reijerse, S. P. J. Albracht, E. C. Hatchikian, W. Lubitz, J. Am. Chem. Soc. 2007, 129, 11447-58.

[15] A. Adamska-Venkatesh, D. Krawietz, J. F. Siebel, K. Weber, T. Happe, E. Reijerse, W. Lubitz, J. Am. Chem. Soc. 2014, 136, 11339-11346.

[16] C. Sommer, A. Adamska-venkatesh, K. Pawlak, J. A. Birrell, O. Rüdiger, E. J. Reijerse, W. Lubitz, J. Am. Chem. Soc. 2017, 139, 1440-1443.

[17] M. Senger, S. Mebs, J. Duan, O. Shulenina, K. Laun, L. Kertess, F. Wittkamp, U.-P. Apfel, T. Happe, M. Winkler, et al., Phys. Chem. Chem. Phys. 2017, in press.

[18] S. Katz, J. Noth, M. Horch, H. S. Shafaat, T. Happe, P. Hildebrandt, I. Zebger, Chem. Sci. 2016, 7, 6746-6752.

[19] A. Adamska-Venkatesh, A. Silakov, C. Lambertz, O. Rüdiger, T. Happe, E. Reijerse, W. Lubitz, Angew. Chemie 2012, 51, 11458-11462.

[20] S. Mebs, K. Laun, M. Senger, J. Duan, F. Wittkamp, U.-P. Apfel, T. Happe, M. Winkler, S. T. Stripp, M. Haumann, J. Am. Chem. Soc. 2017, 139, 12157-12160.

[21] P. Chernev, C. Lambertz, A. Brünje, N. Leidel, K. G. V.
Sigfridsson, R. Kositzki, S. Y. Chung-Hung Hsieh, M. D. Rafael Schiwon, C. Limberg, T. Happe, et al., Inorg. Chem. 2014, 53, 12164-12177.

[22] J. Esselborn, N. Muraki, K. Klein, V. Engelbrecht, N Metzler-Nolte, U.-P. Apfel, E. Hofmann, G. Kurisu, T. Happe, Chem. Sci. 2016, 7, 959-968.

[23] J. F. Siebel, A. Adamska-venkatesh, K. Weber, S. Rumpel, E. Reijerse, W. Lubitz, Biochemistry 2015, 54, 1474-1483. J. Noth, J. Esselborn, J. Güldenhaupt, A. Brünje, A. Sawyer, U.-P. Apfel, K. Gerwert, E. Hofmann, M. Winkler, T. Happe, Angew. Chemie 2016, 55, 8396-8400.

[25] A. L. De Lacey, C. Stadler, C. Cavazza, E. C. Hatchikian, V. M. Fernandez, J. Am. Chem. Soc. 2000, 122, 1123211233.

[26] W. Roseboom, A. L. De Lacey, V. M. Fernandez, E. C. Hatchikian, S. P. J. Albracht, J. Biol. Inorg. Chem. 2006, 11, 102-118.

[27] D. W. Mulder, M. W. Ratzloff, E. M. Shepard, A. S. Byer, S. M. Noone, J. W. Peters, J. B. Broderick, P. W. King, J. Am. Chem. Soc. 2013, 135, 6921-9.

[28] M. Senger, S. Mebs, J. Duan, F. Wittkamp, U. Apfel, J. Heberle, M. Haumann, S. T. Stripp, Proc. Natl. Acad. Sci. U. S. A. 2016, 113, 8454-8459.

[29] V. Fourmond, C. Greco, K. Sybirna, C. Baffert, P.-H. Wang, P. Ezanno, M. Montefiori, M. Bruschi, I. Meynial-Salles, P. Soucaille, et al., Nat. Chem. 2014, 6, 336-42.

[30] C. Greco, M. Bruschi, L. De Gioia, U. Ryde, Inorg. Chem. 2007, 46, 15-16.

[31] A. R. Finkelmann, M. T. Stiebritz, M. Reiher, Chem. Sci. 2014, 5, 215-221.

[32] A. Jablonskytè, L. R. Webster, T. R. Simmons, J. A. Wright, C. J. Pickett, J. Am. Chem. Soc. 2014, 136, 13038-13044. G. Zampella, P. Fantucci, L. De Gioia, J. Am. Chem. Soc. 2009, 131, 10909-10917.

[34] G. Filippi, F. Arrigoni, L. Bertini, L. De Gioia, G. Zampella, Inorg. Chem. 2015, 54, 9529-9542.

[35] S. Mebs, R. Kositzki, J. Duan, M. Senger, F. Wittkamp, U.P. Apfel, T. Happe, S. T. Stripp, M. Winkler, M. Haumann, $B B A$ - Bioenerg. 2017, in press.

[36] M. L. Singleton, N. Bhuvanesh, J. H. Reibenspies, M. Y. Darensbourg, Angew. Chemie - Int. Ed. 2008, 47, 94929495.

[37] C. Greco, L. De Gioia, Inorg. Chem. 2011, 50, 6987-6995. [38] J. M. Camara, T. B. Rauchfuss, Nat. Chem. 2011, 4, 2630. 


\section{Entry for the Table of Contents}

\section{COMMUNICATION}

FTIR spectro-electrochemistry on [FeFe]-hydrogenases proves protoncoupled electron transfer reactivity in the formation of the one-electron reduced cofactor species Hred'.

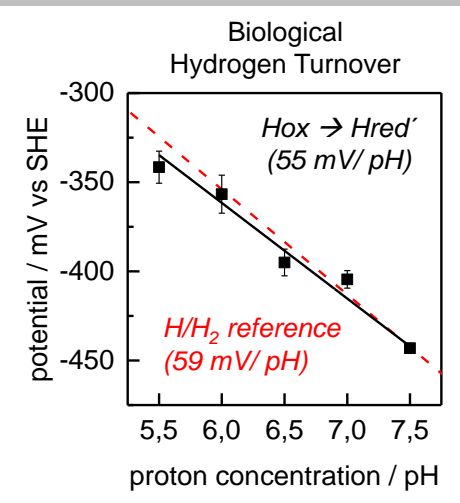

Moritz Senger, Konstantin Laun, Florian Wittkamp, Jifu Duan, Thomas Happe, Martin Winkler, Ulf-Peter Apfel*, Sven T. Stripp **

Page No. - Page No.

Reduction of the Catalytic [4Fe-4S] Cluster in [FeFe]-hydrogenases is coupled to Proton Transfer 